\title{
Proportional Assist Ventilation Decreases Thoracoabdominal Asynchrony and Chest Wall Distortion in Preterm Infants
}

\author{
GABRIEL MUSANTE, ANDREAS SCHULZE, TILO GERHARDT, RUTH EVERETT, \\ NELSON CLAURE, PETER SCHALLER, AND EDUARDO BANCALARI \\ Department of Pediatrics, Division of Neonatology, University of Miami School of Medicine, \\ Miami, Florida, U.S.A.
}

\begin{tabular}{|c|c|}
\hline \multicolumn{2}{|c|}{ ABSTRACT } \\
\hline $\begin{array}{l}\text { Thoracoabdominal asynchrony (TAA) and chest wall distor- } \\
\text { tion (CWD) are commonly seen in preterm infants secondary to } \\
\text { a highly compliant rib cage and poor compensation of distorting } \\
\text { forces by inspiratory rib cage muscles. Continuous positive } \\
\text { airway pressure (CPAP) reduces TAA and CWD by stenting the } \\
\text { chest wall. We hypothesized that application of positive airway } \\
\text { pressure only during inspiration and in proportion to an infant's } \\
\text { inspiratory effort should have a similar but more pronounced } \\
\text { effect than CPAP alone. A ventilator providing airway pressure } \\
\text { changes in proportion to flow and volume generated by an infant } \\
\text { (proportional assist ventilation) was used to unload the respira- } \\
\text { tory pump during inspiration. Ten preterm infants were studied } \\
\text { [birth weight, } 745 \text { ( } 635-1175) \text { g; gestational age, } 26.5 \text { ( } 24-31 \text { ) } \\
\text { wk; postnatal age } 3 \text { ( } 1-7 \text { ) d; medium (range)]. TAA and CWD } \\
\text { were determined by respiratory inductive plethysmography. } \\
\text { TAA was expressed as the phase angle between the rib cage and } \\
\text { abdominal motion and CWD as the total compartmental dis- } \\
\text { placement ratio. In addition, we measured tidal volume with a } \\
\text { pneumotachograph and esophageal and airway pressure deflec- } \\
\text { tions with pressure transducers. Measurements were obtained } \\
\text { during alternating periods of CPAP and two different degrees of } \\
\text { support (Gain } 1=1.09 \pm 0.68 \text {, Gain } 2=1.84 \pm 0.84 \text { cm } \\
\mathrm{H}_{2} \mathrm{O} / \mathrm{mL} \text { ) that were provided by a proportional assist ventilator. } \\
\text { Phase angle and the total compartmental displacement ratio } \\
\text { decreased with increasing gain compared with CPAP alone. Peak } \\
\text { airway pressure increased from } 0.6 \text { to } 3.8 \text { to } 7.6 \text { cm } \mathrm{H}_{2} \mathrm{O} \text { above }\end{array}$ & $\begin{array}{l}\text { positive end-expiratory pressure (PEEP) with CPAP, Gain 1, and } \\
\text { Gain 2, respectively, as tidal volume increased from } 2.8 \text { to } 4.1 \text { to } \\
4.7 \mathrm{~mL} / \mathrm{kg} \text {. Esophageal pressure changes decreased only little } \\
\text { with increasing gain. Chest wall excursion increased and abdom- } \\
\text { inal movement decreased, indicating a redistribution of tidal } \\
\text { volume between chest and abdomen. We conclude that propor- } \\
\text { tional assist ventilation reduces TAA and CWD by generating a } \\
\text { small increase in airway pressure that occurs in synchrony and in } \\
\text { proportion to each inspiratory effort. (Pediatr Res 49: 175-180, } \\
\text { 2001) } \\
\text { ABD, area under the curve of the abdominal band signal } \\
\text { during inspiration } \\
\text { BW, birth weight } \\
\text { CPAP, continuous positive airway pressure } \\
\text { CWD, chest wall distortion } \\
\text { ETT, endotracheal tube } \\
\text { PAV, proportional assist ventilation } \\
\text { Paw, airway pressure change } \\
\text { Pes, esophageal pressure change } \\
\text { RC, area under the curve of the rib cage band signal during } \\
\text { inspiration } \\
\text { TAA, thoracoabdominal asynchrony } \\
\text { TCD ratio, total compartmental displacement ratio } \\
\text { Vt, tidal volume }\end{array}$ \\
\hline
\end{tabular}

TAA, in which the rib cage and abdomen move out of phase due to inward CWD, are commonly seen in spontaneously breathing preterm infants. TAA and CWD are more pronounced in the presence of decreased lung compliance or increased airway resistance but can also be seen in preterm

Received October 5, 1999; accepted August 15, 2000.

Correspondence: Eduardo Bancalari, M.D., University of Miami School of Medicine, Department of Pediatrics (R-131), Division of Neonatology, P.O. Box 016960, Miami, Florida 33101, U.S.A.

Supported in part by the University of Miami Project Newborn and by Fritz Stephan Biomedical Inc., Gackenbach and Dresden, Germany. infants without lung disease or in term infants during REM sleep (1-4). The phenomenon is caused by mainly two factors: the negativity of the pleural pressure generated during inspiration and the compliance of the chest wall (5-7). For the chest wall to move along the pressure/volume curve seen during passive inflation of the respiratory system, active compensation from the inspiratory chest wall muscles, counteracting the distorting pleural force, is necessary (8). It has been shown that the more immature the infants are, the less well developed is their active compensation (9). It may be completely absent in very immature infants, leading to a $180^{\circ}$ phase shift between 
abdominal and chest wall movement, i.e. the chest wall moves inward as the abdomen moves outward and vice versa. Frequently, a partial compensation occurs in the second half of inspiration so that inward movement of the chest wall is only seen in the beginning of inspiration.

As a consequence of inspiratory CWD, the $\mathrm{Vt}$ is reduced and the diaphragm has to descend further with every breath to compensate for the lost volume. Under these conditions, diaphragmatic work increases and can be several times the work necessary to distend the lungs. This situation predisposes to diaphragmatic fatigue and respiratory failure and may lead to apnea $(10,11)$.

With increasing maturity, diaphragmatic work decreases and eventually becomes less than the total work done on the lungs, because chest wall muscles compensate for the distorting force of the diaphragm and provide part of the inspiratory work (10).

The application of CPAP in infants with CWD has been shown to reduce the degree of asynchrony; the higher the CPAP, the lower the indices of distortion (12). The observation has been explained by a stenting action of an increased lung volume, preventing collapse of the chest wall during inspiration. CPAP at a level high enough to prevent CWD (12-14 cm $\mathrm{H}_{2} \mathrm{O}$ ) may have unwanted cardiovascular side effects and will decrease lung compliance and Vt by pulmonary overdistention and, in addition, will reduce respiratory rate by triggering vagally mediated reflexes (13-15). To reduce these side effects, ideally, the stenting pressure should be applied only during inspiration and in proportion to the inspiratory effort.

A ventilatory support method that could satisfy these requirements is the newly developed concept of PAV (16-18). PAV provides inspiratory support proportional to the infant's inspiratory effort by continuously adjusting inspiratory pressure in proportion to the volume and flow generated by the infant. Frequency, inspiratory duration, and peak pressure are not fixed but determined by the patient, thus preserving the breathing strategy of his/her own respiratory center.

The purpose of the present study was to test the efficiency of a newly developed PAV system for neonates in reducing TAA and CWD in very-low-birth-weight preterm infants. To test this, we evaluated the thoracoabdominal motion profiles in a group of intubated preterm infants during CPAP and two different degrees of PAV. We hypothesized that the airway pressure applied by the PAV system during inspiration will reduce the degree of TAA and CWD compared with the situation of CPAP alone.

\section{METHODS}

This study is part of the first trial testing the efficiency and safety of PAV in very-low-birth-weight infants. The device used for PAV was approved for the study under an investigator-initiated Investigational Device Exemption from the FDA (IDE \# G950100). The present study was approved by the Institutional Review Board, and parental informed consent was obtained for each infant studied.

Infants meeting the following criteria were eligible for the study: 1) BW, 600-1200 g; 2) postnatal age 2-10 d; 3) presence of spontaneous respiratory efforts; 4) in the recovery phase of respiratory failure, on low intermittent mandatory ventilation settings ( $<20$ breaths per minute). The presence of CWD was not an entry criterion. Exclusion criteria included the following: 1) major congenital anomalies; 2) unstable hemodynamic status, defined as mean arterial blood pressure outside a specified reference range (19) any time during the previous $12 \mathrm{~h}$; 3) an ETT leak $>20 \%$ of the Vt, measured as the difference between the inspiratory and expiratory volumes with the regular ventilator setting as chosen by the clinical team.

We studied 10 preterm infants; their median BW was $745 \mathrm{~g}$ (range, 635-1175 g), their median postnatal age was $3 \mathrm{~d}$ (range, 1-7 d), and their median gestational age was $26.5 \mathrm{wk}$ (range, 24-31 wk). Four of the infants had received exogenous surfactant treatment (Survanta, Ross Inc., Columbus, $\mathrm{OH}$, U.S.A.); eight of the mothers had received steroids before delivery.

Measurement of thoracoabdominal motion and lung mechanics. Thoracoabdominal motion was assessed using respiratory inductive plethysmography (Respitrace Plus, Noninvasive Monitoring Systems, Miami Beach, FL, U.S.A.). Two transducer bands of $1.5-\mathrm{cm}$ width were wrapped circumferentially around the rib cage and abdomen at the level of the nipples and umbilicus, respectively. The position of the bands was secured with tape. The bands provide voltage changes that are proportional to the changes in their cross-sectional area and thus reflect the volume changes in the rib cage and abdominal compartments. Calibration was achieved by the built-in qualitative diagnostic calibration procedure that determines the relative electrical gains for the two signals $(20,21)$. This procedure takes approximately $5 \mathrm{~min}$ and was done while the infants were in the supine position, lying quietly in their incubators. During the study, the infant's body position and the placement of the bands remained unchanged. No attempt was made to calibrate the Respigraph signal against actual volume measurements because relative motion and timing, not absolute volume changes of the rib cage and abdomen, were the variables of interest. TAA was expressed by the phase angle that reflects the delay in outward motion of the rib cage compared with the abdomen. The phase angle was expressed in degrees assuming that the total respiratory cycle has $360^{\circ}$ (complete asynchrony with negative chest wall excursion throughout the inspiratory phase would result in a phase angle of $180^{\circ}$ ). The areas under the curve of the abdominal and rib cage band signals during the inspiratory phase (ABD and $\mathrm{RC}$, respectively) were obtained for each breath. TCD was measured by the ratio between the sum of the absolute values of ABD and RC and their true sum (sign included) (22). The TCD ratio is 1.0 when no chest wall negativity occurs during inspiration, and it increases above 1.0 in the presence of CWD.

A fluid-filled $8 \mathrm{~F}$ infant feeding tube was placed into the lower third of the esophagus for esophageal manometry. An end-expiration occlusion test was performed to verify the full transmission of pleural pressure changes to the esophagus (23). The catheter was flushed periodically with distilled water to prevent gas bubble formation and keep its patency. The airway pressure signal was obtained from a side port of the ETT connector. The pressure transducers (Sorenson Transpac 
Transducers, Abbot Critical Care Systems, North Chicago, IL, U.S.A.) were calibrated with a water manometer. The airflow signal was obtained from the analog output of the ventilator's pneumotachograph, the signal having been previously validated against a flow calibration device (Matheson model 8100, Matheson, Secaucus, NJ, U.S.A.). Vt was obtained by integration of the flow signal. Breath-to-breath Pes was determined as the peak-to-peak difference in the sinusoidal esophageal pressure trace during a respiratory cycle. Paw was determined as the peak inspiratory change in airway pressure above positive end-expiratory pressure (PEEP). Calculation of lung compliance and airway resistance was based on the Mead and Wittenberger method $(24,25)$.

All analog signals were digitized at a rate of $100 \mathrm{~Hz}$ and recorded on disk by using data acquisition software (DATAQ Instruments Inc., Akron, OH, U.S.A.).

Ventilator. A Stephanie infant ventilator (F. Stephan Medizintechnik $\mathrm{GmbH}$, Gackenbach and Dresden, Germany) was used during the study. This device has been described elsewhere $(26,27)$. It is a servocontrolled system that uses a pneumotachograph placed between the ETT and the ventilator circuit. In addition to conventional mechanical ventilation and CPAP, it can provide PAV. In this mode, the airway pressure is servocontrolled throughout the inspiratory phase and changes instantaneously in proportion to the volume (volume assist or elastic unloading) and the flow (flow assist or resistive unloading) generated by the infant.

During PAV, the gains for resistive unloading [in $\mathrm{cm} \mathrm{H}_{2} \mathrm{O} /$ $(\mathrm{L} / \mathrm{s})]$ and elastic unloading (in $\mathrm{cm} \mathrm{H}_{2} \mathrm{O} / \mathrm{mL}$ ) can be set individually but must be below the subject's resistance and elastance, respectively, to prevent overcompensation.

Protocol. Measurements were obtained in the supine position during periods of CPAP $\left(4-5 \mathrm{~cm} \mathrm{H}_{2} \mathrm{O}\right)$ and two different degrees of unloading (Gain 1 and Gain 2). CPAP and the two degrees of mechanical unloading were alternated randomly with the CPAP period lasting from $30 \mathrm{~s}$ to $2 \mathrm{~min}$ as tolerated, and the PAV periods up to $15 \mathrm{~min}$. Regardless of the randomly determined sequence, CPAP was also applied before each PAV period to prevent carryover effects from the other modes of ventilatory support.

Resistive unloading was set at $20 \mathrm{~cm} \mathrm{H}_{2} \mathrm{O} / \mathrm{L} / \mathrm{s}$, which is approximately the resistance of a size 2.5 ETT, in all infants. This was done because an elevated pulmonary resistance is uncommon in the recovery phase of respiratory distress in neonates, so that this degree of resistive unloading was estimated to "leave" the infants with their normal endogenous pulmonary resistance.

In infants with alveolar disease, the larger part of the inspiratory work is used to overcome the elastic forces of the lung. The higher the pulmonary elastance, the higher the effort has to be to generate a normal $\mathrm{Vt}$ and the higher the CWD force will be. To prevent CWD by counteracting the distorting force, the distending airway pressure provided by PAV has to be proportional to the underlying pulmonary elastance. An infant of $1 \mathrm{~kg} \mathrm{BW}$ with normal lungs has an elastance of approximately $0.67 \mathrm{~cm} \mathrm{H}_{2} \mathrm{O} / \mathrm{mL}$ and, therefore, needs to generate 0.67 $\mathrm{cm} \mathrm{H}_{2} \mathrm{O}$ of pleural pressure change for a 1-mL volume change. No ventilatory assistance was given in this situation to prevent the risks of overcompensation. But if elastance was higher, for example $2.0 \mathrm{~cm} / \mathrm{H}_{2} \mathrm{O} / \mathrm{mL}$, assistance to overcome the additional elastance was provided. In this case, $2.0-0.67=1.33$ $\mathrm{cm} \mathrm{H}_{2} \mathrm{O}$ of airway pressure per milliliter of Vt generated by the infant was provided by the ventilator for Gain 2 and half of this for Gain 1.

Pulmonary elastance was calculated before the study in each infant from $\mathrm{Vt}$ and transpulmonary pressure by using the Mead and Whittenberger method (24). These values were then used for the determination of Gain 1 and Gain 2 during PAV as described above.

A limit for inspiratory pressure of $20 \mathrm{~cm} \mathrm{H}_{2} \mathrm{O}$ was set to prevent pressure runaway in case of elastic overcompensation.

Statistical analysis. Thoracoabdominal motion and pulmonary mechanics were compared during CPAP and Gain 1 and Gain 2 of mechanical unloading. Twenty to 40 breaths obtained during regular quiet breathing and free of artifact were selected from each infant for the three different modes. The analyzed breaths had to fulfill the following criteria: 1) inspiratory and expiratory volume within $20 \%$ of each other; 2) baseline esophageal pressure determined at zero flow in the beginning and end of a breath at the same level as for the previous and following breaths; 3) Vt within the range of 2-7 $\mathrm{mL} / \mathrm{kg} ; 4)$ regular phasic breathing with inspiratory and expiratory times in the proper ratio; and 5) absence of movement artifact on the inductance plethysmograph trace. All breaths fulfilling these criteria were analyzed.

Results are given in mean \pm SD or median (range). Oneway repeated measures ANOVA or Friedman repeated measures ANOVA on Ranks was used to compare data for CPAP, Gain 1, and Gain 2. Student-Newman-Keuls post hoc method was applied to isolate differences among the three modes (Sigma Stat for Windows, Jandel Corporation, Corte Madera, CA, U.S.A.).

$p$ values $<0.05$ were considered statistically significant.

\section{RESULTS}

The mean elastic compensation used in the 10 infants was $1.84 \pm 0.84 \mathrm{~cm} \mathrm{H}_{2} 0 / \mathrm{mL}$ for Gain 2 and $1.09 \pm 0.68 \mathrm{~cm}$ $\mathrm{H}_{2} \mathrm{O} / \mathrm{mL}$ for Gain 1. The mean lung compliance of the infants was $0.67 \pm 0.43 \mathrm{~mL} / \mathrm{cm} \mathrm{H} \mathrm{H}_{2} \mathrm{O} / \mathrm{kg}$ [lung elastance $1.49 \mathrm{~cm}$ $\left.\mathrm{H}_{2} \mathrm{O} /(\mathrm{mL} / \mathrm{kg})\right]$. The mean total pulmonary resistance was 108 $\pm 36 \mathrm{~cm} \mathrm{H}_{2} \mathrm{O} / \mathrm{L} / \mathrm{s}$. During CPAP, TAA and CWD were present in each infant and decreased significantly during the application of PAV. This decrease was more striking with the higher level of assist. The means for the measurements of phase angle and TCD ratio under the different conditions of CPAP, Gain 1, and Gain 2 are given in Table 1. On Gain 2, the TCD ratio was slightly above 1.0, indicating minimal distortion, but there still was a short phase lag of rib cage movement during early inspiration. PAV led to a significant increase in chest wall and a decrease in abdominal excursion, indicating a redistribution of the Vt within the lung.

Figures 1 and 2 show the changes in phase angle and TCD ratio, respectively, for individual infants under the three different conditions of ventilatory support. The improvement in 
Table 1. Data on thoracoabdominal motion profiles, pressures, and

\begin{tabular}{lccc}
\multicolumn{4}{c}{$V_{T}$ for $C P A P$ and Gains 1 and 2 of unloading } \\
\hline & CPAP & GAIN 1 & GAIN 2 \\
\hline $\begin{array}{l}\text { Phase angle } \\
\quad \text { degrees) }\end{array}$ & $99.2 \pm 39.1$ & $71.8 \pm 36.9 \dagger$ & $45.2 \pm 16.0 \dagger \|$ \\
TCD ratio & $1.70(1.15-2.81)$ & $1.27(1.04-1.97)^{*}$ & $1.12(1.03-1.49)^{* \dagger}$ \\
Pes $\left(\mathrm{cm} \mathrm{H} \mathrm{H}_{2} \mathrm{O}\right)$ & $4.0(2.7-5.9)$ & $3.8(2.3-5.1)$ & $2.4(1.2-4.8)^{* \dagger}$ \\
Paw $\left(\mathrm{cm} \mathrm{H}_{2} \mathrm{O}\right)$ & $0.6 \pm 0.2$ & $3.8 \pm 1.9^{* *}$ & $7.6 \pm 3.2^{* *}+$ \\
$\mathrm{V}_{\mathrm{T}}(\mathrm{mL} / \mathrm{kg})$ & $2.8(2.1-4.4)$ & $4.1(3.0-5.6)^{*}$ & $4.7(4.0-6.4)^{*}$ \\
$\mathrm{RC}$ & $-13 \pm 29$ & $19 \pm 35^{*}$ & $41 \pm 22^{* \dagger}$ \\
$\mathrm{ABD}$ & $133 \pm 28$ & $138 \pm 30$ & $118 \pm 25^{*}+$ \\
\hline
\end{tabular}

Data are presented as mean $\pm \mathrm{SD}$.

$* p<0.05$ compared to CPAP.

$\pm p<0.05$ compared to Gain 1 .

** $p<0.001$ compared to CPAP.

$\S p<0.001$ compared to Gain 1 .

$\dagger p<0.005$ compared to CPAP.

$\| p<0.005$ compared to Gain 1 .

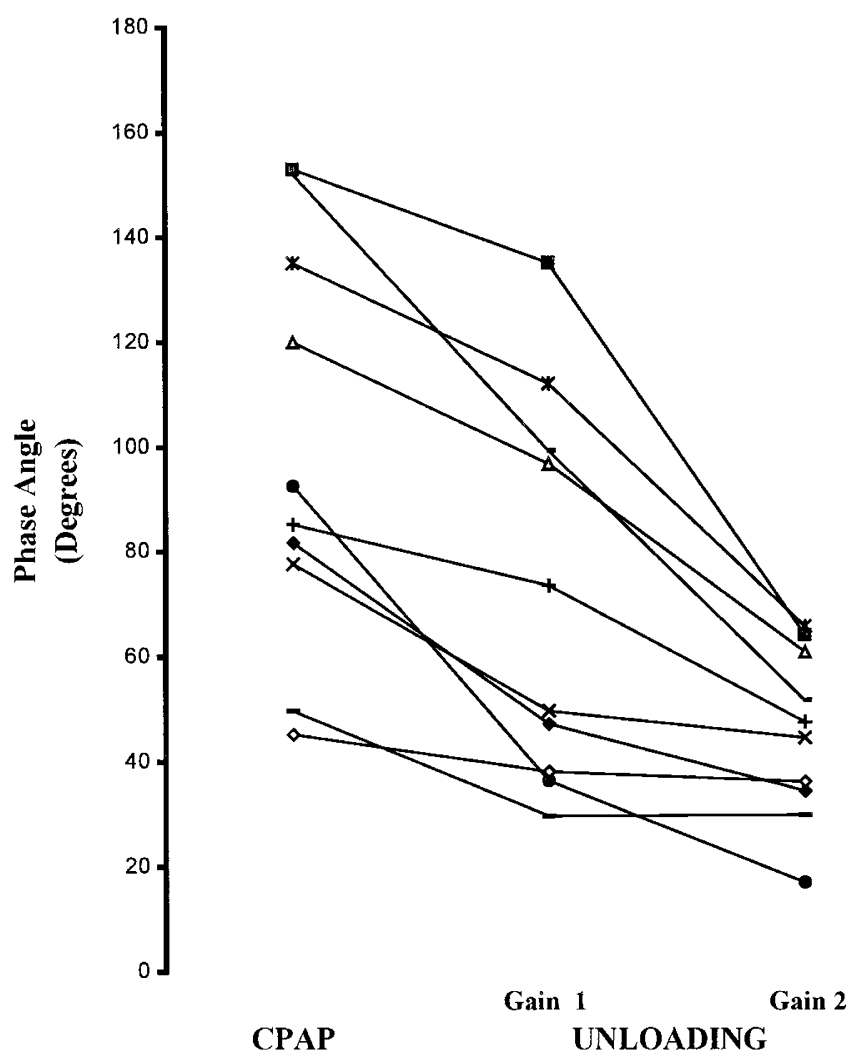

Figure 1. Changes in phase angle (in degrees) for individual infants during CPAP, Gain 1, and Gain 2.

phase angle and TCD ratio with PAV was more pronounced in infants with the higher TAA and CWD initially.

The improvement in thoracoabdominal motion with PAV was accompanied by a small decrease in esophageal pressure deflection per breath and an increase in Paw per breath and in Vt (see Table 1).

These observations are further illustrated during a switch from PAV to CPAP in an individual infant (Fig. 3). When PAV is discontinued, changes in airway pressure cease, respiratory flows and Vt decrease, and esophageal pressure deflections increase as does the negative movement of the rib cage during

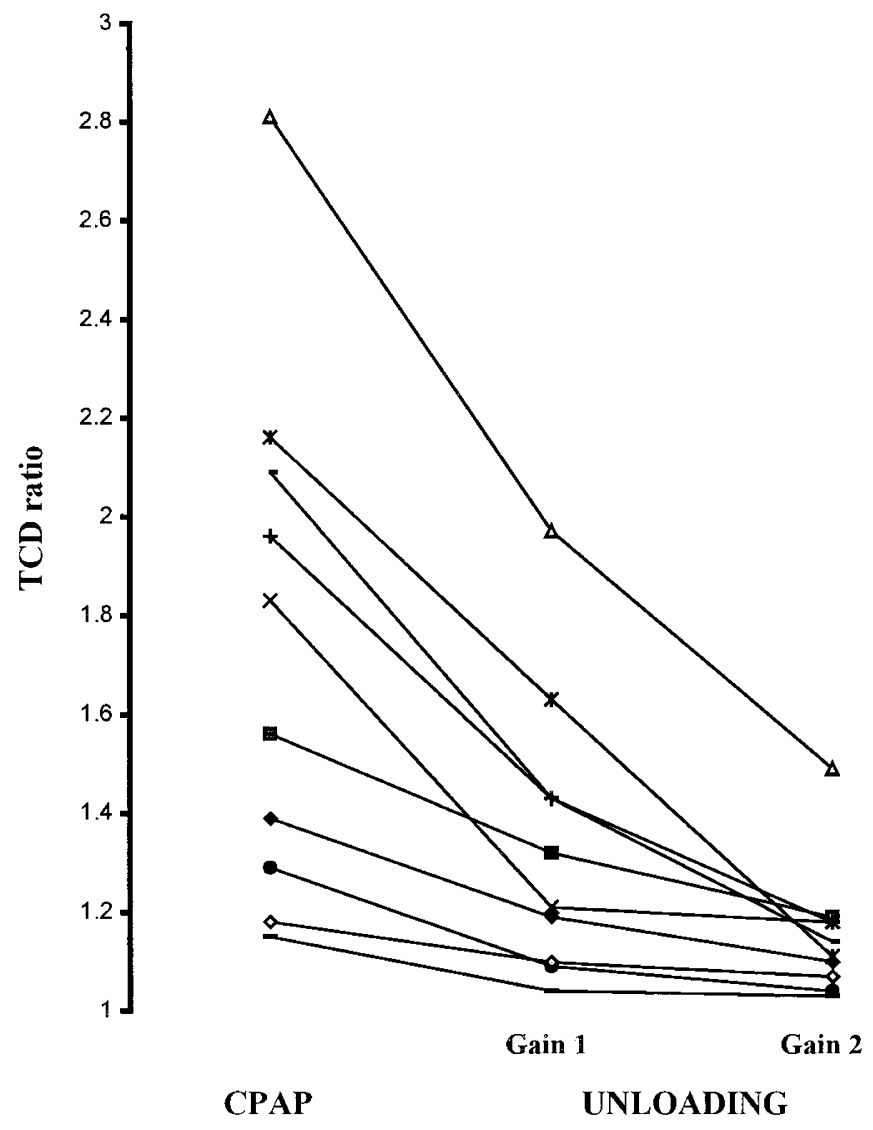

Figure 2. Changes in TCD ratio for individual infants during CPAP, Gain 1, and Gain 2.

inspiration, indicating an increase in CWD. The abdominal excursions increase, compensating partially for the volume loss secondary to CWD.

\section{DISCUSSION}

The results indicate that the small increase in airway pressure provided by PAV during inspiration was enough to counteract the distorting effect of pleural pressure. The TCD ratio approached the normal range; the phase angle improved, but there was still some lag in chest wall excursion in the beginning of inspiration.

The observed improvement in TAA and CWD may be due to a reduction in peak breath-to-breath negativity in Pes during PAV compared with the CPAP mode (28). However, this reduction was too small, approximately $1.6 \mathrm{~cm} \mathrm{H}_{2} \mathrm{O}$ during Gain 2 and only $0.2 \mathrm{~cm} \mathrm{H}_{2} \mathrm{O}$ during Gain 1, to fully explain the improvement in TAA and CWD.

Furthermore, inspiratory changes in Pes reflecting pleural pressure changes are underestimated during any ventilatory support, because part of the pressure applied to the airways during inspiration is transmitted to the intrathoracic structures. Thus, the esophageal pressure baseline increases progressively from beginning to the end of inspiration. The peak negativity in Pes observed at the end of inspiration, therefore, needs to be corrected for this upward shift in baseline.

The increase in esophageal pressure baseline during the application of positive airway pressure is small in preterm 
2/min 0$]$
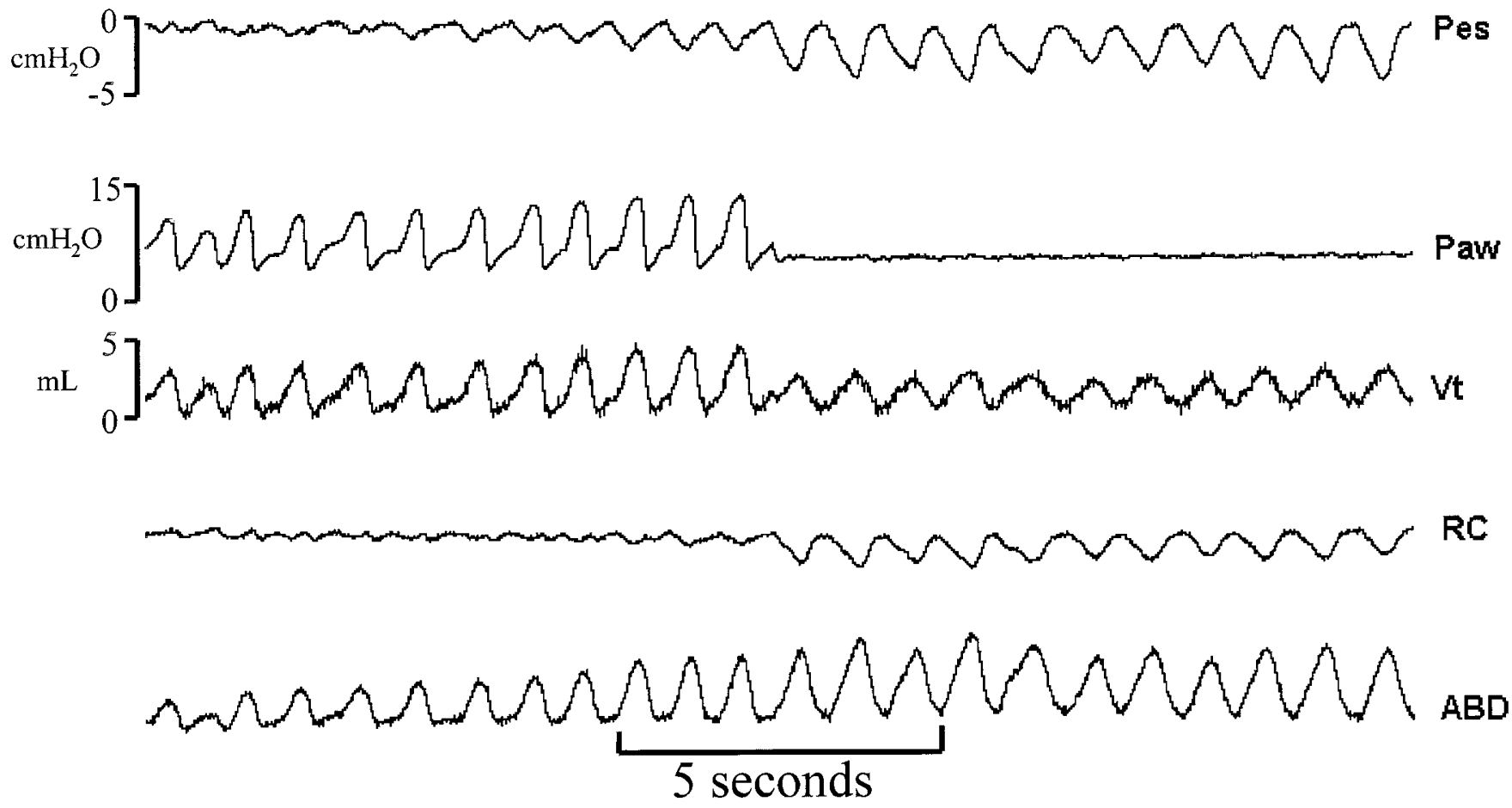

Figure 3. Tracings from a patient showing the change in breathing pattern after switching from PAV to CPAP.

infants because of their high chest wall compliance, not more than 10 to $20 \%$ of the airway pressure (6). Using Paw of 3.8 and $7.6 \mathrm{~cm} \mathrm{H}_{2} \mathrm{O}$, the increase in esophageal pressure baseline can be estimated as 0.6 and $1.1 \mathrm{~cm} \mathrm{H}_{2} \mathrm{O}$ during Gains 1 and 2, respectively. This brings the corrected Pes changes during PAV close to the ones observed during CPAP. The improvement in TAA and CWD during PAV, therefore, cannot be explained by a decrease in Pes.

The measurement of Pes in the presence of CWD has been described as unreliable, because it may reflect local pleural pressure changes rather than a mean pressure change (29). However, we reexamined this question recently and found that CWD does not affect Pes measurements adversely $(30,31)$. Therefore, it can be assumed that the measurements provided here are a reliable reflection of pleural pressure changes.

Most of the remaining distortion during PAV occurred in the beginning of inspiration when Pes negativity was still small and not at the end of inspiration when Pes negativity reached its maximum. This observation suggests two other explanations for the decrease in TAA and CWD during PAV. Active compensation from the inspiratory chest wall muscles may have occurred during the remainder of inspiration stimulated by PAV, or the increasing chest volume generated by the PAV stented the chest wall, counteracting the increasingly distorting negative pleural pressure.
How PAV could stimulate the inspiratory activity of the rib cage muscles is not clear. An increase in this activity has been observed in neonates during any increase in respiratory center output, for example during $\mathrm{CO}_{2}$ exposure (32). In our infants, however, a decrease in respiratory center output can be expected from the unloading of the respiratory system provided by PAV $(28,33)$. Furthermore, it is not known how much compensation rib cage muscles can generate during inspiration in very immature infants and whether this compensation can be stimulated and increased at all. Therefore, the stenting action of a larger lung volume supporting the chest wall and preventing its collapse during inspiration is probably the main effect by which PAV reduces TAA and CWD.

The presence of CWD resulted in a reduced $\mathrm{Vt}$, an increased abdominal volume change, and increased diaphragmatic work. With the decreased CWD during PAV, abdominal volume changes and, in consequence, diaphragmatic work decreased, whereas Pes changes remained in the same range. This is an improvement in the effectiveness of the respiratory pump similar to that observed in preterm infants with maturation (9).

External loads of the respiratory system as well as internal loads from changes in pulmonary mechanics secondary to a disease process increase TAA in neonates and infants $(2,7$, 34). The removal of the load has been shown to improve synchrony and distortion $(2,34)$. PAV provided unloading of 
the respiratory system by removal of the resistive load of the ETT and the disease-related internal elastic load of the lungs. The reduction in TAA and CWD can, therefore, also be explained by the unloading of the respiratory system provided by PAV (28). The infants studied, however, had only mild pulmonary function abnormalities, so that the degree of unloading provided was small. As shown above, it did not result in a sizable reduction in Pes change, so that the main effect of $\mathrm{PAV}$ in reducing TAA and CWD remains the stenting effect of an increased thoracic lung volume.

A decrease in TAA has been observed previously in extubated preterm infants after nasally applied synchronized intermittent mandatory ventilation (35). In this study, no measurements of Vt and Pes are given, so that the degree of respiratory unloading and potential decrease in respiratory drive cannot be judged. Another study reported a reduction in TAA and CWD in intubated full-term infants during pressure support ventilation (36). No compliance and resistance measurements were given, but TAA and CWD were mild, suggesting that the infants had no or little lung disease. Pressure support significantly reduced respiratory rate, indicating a reduction in respiratory drive, but no esophageal pressure measurements were done.

In principle, all types of ventilatory support, synchronized or nonsynchronized, can reduce the degree of CWD, mainly by reducing the infant's work of breathing and, thus, breath-tobreath pleural pressure changes. However, this is achieved by delivering breaths with fixed peak pressure and inspiratory time, overcompensating for the infant's elastance and resistance. The pressure costs to achieve the same reduction in CWD are, therefore, much higher than during PAV.

In summary, in very immature infants with severe TAA and CWD, PAV improves synchronization of motion between abdomen and chest wall, allowing a breathing pattern characteristic of more mature infants. Abdominal excursion and diaphragmatic work decreased and chest wall excursion increased, whereas pleural pressure changes remained largely unchanged. We speculate that this improvement in breathing pattern makes the diaphragm more efficient, preventing fatigue and respiratory failure, especially when exposed to increasing respiratory loads.

\section{REFERENCES}

1. Carlo WA, Martin RJ, Versteegh FGA, Goldman MD, Robertson SS, Fanaroff AA 1982 The effect of respiratory distress syndrome on chest wall movements and respiratory pauses in preterm infants. Am Rev Respir Dis 126:103-107

2. Allen JL, McDowell K, Wolfson MR, Shaffer TH 1990 Thoracoabdominal asynchrony in infants with airflow obstruction. Am Rev Respir Dis 141:337-342

3. Gaultier C, Praud JP, Canet E, Delaperche MF, D'Allest AM 1987 Paradoxical inward rib cage movement during rapid eye movement sleep in infants and young children. J Dev Physiol 9:391-397

4. David M, Sankaran K, MacCallum M, Cates D, Rigatto H 1976 Effect of sleep state on chest distortion and on ventilatory response to $\mathrm{CO}_{2}$ in neonates. Pediatr Res 13:982-986

5. Allen JL, Greenspan JS, Deoras KS, Keklikian E, Wolfson MR, Shaffer TH 1991 Interaction between chest wall motion and lung mechanics in normal infants and infants with bronchopulmonary dysplasia. Pediatr Pulmonol 11:37-43
6. Gerhardt T, Bancalari E 1980 Chest wall compliance in full-term and premature infants. Acta Paediatr Scand 69:359-364

7. Deoras KS, Greenspan JS, Wolfson MR, Keklikian E, Shaffer TH, Allen JL 1992 Effects of inspiratory resistive loading on chest wall motion and ventilation: differences between preterm and full-term infants. Pediatr Res 32:589-594

8. Mortola JP, Saetta M, Fox G, Smith B, Weeks S 1985 Mechanical aspects of chest wall distortion. J Appl Physiol 59:295-304

9. Heldt GP 1988 Development of stability of the respiratory system in preterm infants. J App Physiol 65:441-444

10. Heldt GP, McIlroy MB 1987 Distortion of chest wall and work of diaphragm in preterm infants. J Appl Physiol 62:164-169

11. Guslits BG, Gaston SE, Bryan MH, England SJ, Bryan AC 1987 Diaphragmatic work of breathing in premature human infants. J Appl Physiol 62:1410-1415

12. Locke R, Greenspan JS, Schaffer TH, Rubenstein SD, Wolfson MR 1991 Effect of nasal CPAP on thoracoabdominal motion in neonates with respiratory insufficiency. Pediatr Pulmonol 11:259-264

13. Johnston WE, Vinten-Johansen J, Santamore WP, Case LD, Little WC 1989 Mechanism of reduced cardiac output during positive end-expiratory pressure in the dog. Am Rev Respir Dis 140:1257-1264

14. Philips JB, Beale EF, Howard JE, Jaeger MJ, Eitzman DV 1980 Effect of positive end-expiratory pressure on dynamic respiratory compliance in neonates. Biol Neonate 38:270-275

15. Martin RJ, Okken A, Katona PG, Klaus MH 1978 Effects of lung volume on expiratory time in the newborn infant. J Appl Physiol 45:18-23

16. Younes M 1992 Proportional assist ventilation, a new approach to ventilatory support theory. Am Rev Respir Dis 145:114-120

17. Younes MA, Puddy C, Roberts D, Light RB, Quesada A, Taylor K, Oppenheimer L, Cramp H 1992 Proportional assist ventilation. Results of an initial clinical trial. Am Rev Respir Dis 145:121-129

18. Schulze A, Schaller P, Jonzon A, Sedin G 1993 Assisted mechanical ventilation using elastic unloading: a study in cats with normal and injured lungs. Pediatr Res 34:600-605

19. Stork EK, Carlo WA, Kliegman RM, Fanaroff AA 1984 Hypertension redefined for critically ill neonates. Pediatr Res 18:321A(abstr)

20. Sackner MA, Watson H, Belsito AS, Feinerman D, Suarez M, Gonzalez G, Bizousky F, Krieger B 1989 Calibration of respiratory inductive plethysmography during natural breathing. J Appl Physiol 66:410-420

21. Adams JA, Zabaleta IA, Stroh D, Johnson P, Sackner MA 1993 Tidal volume measurements in newborns using respiratory inductive plethysmography. Am Rev Respir Dis 148:585-588

22. Sackner MA, Gonzalez H, Rodriguez M, Belsito A, Sackner DR, Grenvik S 1984 Assessment of asynchronous and paradoxical motion between rib cage and abdomen in normal subjects and in patients with chronic obstructive pulmonary disease. Am Rev Respir Dis 130:588-593

23. Asher MI, Coates AL, Collinge JM, Milic-Emili J 1982 Measurement of pleural pressure in neonates. J Appl Physiol 52:491-494

24. Mead J, Wittenberger JL 1953 Physical properties of human lungs measured during spontaneous respiration. J Appl Physiol 5:779-796

25. Silva Neto G, Gerhardt T, Silberberg A, Claure N, Duara S, Bancalari E 1992 Nonlinear pressure/volume relationship and measurements of lung mechanics in infants. Pediatr Pulmonol 12:146-152

26. Schaller P, Schulze A 1991 A ventilator generating a positive or negative internal compliance. Ups J Med Sci 96:219-234

27. Schulze A, Schaller P, Töpfer A, Kirpalani H 1993 Resistive and elastic unloading to assist spontaneous breathing does not change functional residual capacity. Pediatr Pulmonol 16:170-176

28. Schulze A, Suguihara C, Gerhardt T, Schaller P, Claure N, Everett R, Bancalari E 1998 Effects of respiratory mechanical unloading on thoracoabdominal motion in meconium-injured piglets and rabbits. Pediatr Res 43:191-197

29. LeSoeuf PN, Lopes JM, England SJ, Bryan A 1989 Influence of chest wall distortion on esophageal pressure. J Appl Physiol 67:889-893

30. Silva Neto G, Gerhardt T, Claure N, Duara S, Bancalari E 1995 Influence of chest wall distortion on esophageal catheter position on esophageal manometry in preterm infants. Pediatr Res 37:617-622

31. Silva Neto G, Gerhardt T, Claure N, Duara S, Bancalari E 1995 Effect of chest wall distortion on the measurements of pulmonary mechanics in preterm infants. Pediatr Pulmonol 20:34-39

32. Hershenson MB, Stark AR, Mead J 1989 Action of the inspiratory muscles of the rib cage during breathing in newborn. Am Rev Respir Dis 139:1207-1212

33. Schulze A, Rich W, Schellenberge L, Schaller P, Heldt GP 1998 Effects of different gain settings during assisted mechanical ventilation using respiratory unloading in rabbits. Pediatr Res 44:132-138

34. Sivan Y, Deakers TW, Newth CJL 1990 Thoracoabdominal asynchrony in acute upper airway obstruction in small children. Am Rev Respir Dis 142:540-544

35. Kiciman NM, Andréasson B, Bernstein G, Mannino FL, Rich W, Henderson C, Held GP 1998 Thoracoabdominal motion in newborns during ventilation delivered by endotracheal tube or nasal prongs. Pediatr Pulmonol 25:175-181

36. Tokioka H, Nagano O, Ohta Y, Hirakawa M 1997 Pressure support ventilation augments spontaneous breathing with improved thoracoabdominal synchrony in neonates with congenital heart disease. Anesth Analg 85:789-793 